\title{
A produção legislativa em saúde da Câmara Legislativa do Distrito Federal na Quinta Legislatura (2007-2010)
}

The legislative health production at the Legislative Chamber of the Federal District in the fifth Parliamentary Term (2007-2010)

\section{Ione Silva Barros ${ }^{1}$, Luiz Carlos Romero ${ }^{2}$}

Resumo: O estudo analisa as contribuições da Câmara Legislativa Distrital (CLDF) para a política de saúde do Distrito Federal, caracterizando sua produção legislativa em matéria de saúde e a atuação dos poderes Legislativo e Executivo quanto à iniciativa, proposição, apreciação e aprovação daquelas matérias, no âmbito da $5^{\text {a }}$ legislatura (2007-2010). Trata-se de estudo de natureza exploratória e descritivo, a partir de análise documental. Das 2.515 proposições legislativas que foram apresentadas à CLDF na 5aㅡ Legislatura, 180 tratavam de matéria de saúde. Quanto à espécie normativa, predominaram os projetos de lei ordinária, tanto em termos gerais quanto em matéria de saúde. Quanto ao mérito, observou-se predomínio de proposições tratando de instituir políticas voltadas para o controle ou a atenção a agravos específicos $(38,4 \%)$ e políticas setoriais $(23,4 \%)$, de iniciativa do Legislativo. As matérias de saúde ocuparam com frequência baixa a agenda do Poder Legislativo Distrital na $5^{a}$ Legislatura, e, ao analisá-las, percebe-se que os princípios e mandamentos do SUS são insuficientes para o oferecimento de uma atenção integral, sendo necessário obrigar, por meio de leis específicas, os gestores do SUS a oferecerem os serviços de saúde de que a população necessita.

Palavras-chave: Direito à Saúde, Produção Legislativa, Sistema Único de Saúde.

Abstract: The study examines the contributions of the District Legislative Chamber (CLDF) for health policy of the Federal District, featuring their legislative production on health and the performance of the legislative and executive powers regarding the initiative, proposition, appraisal and approval of those matters within the framework of the 5th parliamentary term (2007-2010). It is an exploratory and descriptive study based on document analysis. Of the 2515 legislative proposals that were presented to the CLDF in the 5th term: 180 with matters of health, and normative laws predominated projects of ordinary bills, both in general terms as well as in terms of health. On the substance, it was observed a predominance of propositions trying to establish policies for the control or attention to specific reportable diseases $(38.4 \%)$ and sectoral policies $(23.4 \%)$ predominated in the legislative initiative. The study concludes there is a low frequency of health issues on the agenda of District Legislature of the 5th term; however, to analyze them, one realizes that the principles and commandments of SUS are insufficient for the delivery of comprehensive care and it is necessary to obligate SUS managers to provide health services that the population needs, through specific laws.

Keywords: Right to Health, Legislative production, Unified Health System.

\footnotetext{
${ }^{1}$ Graduada em Saúde Coletiva pela Universidade de Brasília. Pós-graduada em Direito Sanitário pela Fiocruz Brasília. Mestranda em Saúde Coletiva da Faculdade de Ciências da Saúde - FS/UnB. Pesquisadora do Núcleo de Estudos em Saúde Pública - NESP/UnB. Brasília, DF, Brasil. E-mail: ionesilvabarros81@gmail.com.

${ }^{2}$ Médico. Especialista em Saúde Pública e em Direito Sanitário. Mestre em Saúde Coletiva pela Faculdade de Ciências da Saúde - FS/UnB Brasília, DF, Brasil. E-mail: romero.luizcarlos@gmail.com.
} 
Resumen: Este estudio tiene como finalidad analizar las contribuciones de la Cámara Legislativa Distrital (CLDF) en relación a la política de salud del Distrito Federal (Brasilia). Se ha caracterizado la producción legislativa en materia de salud y la actuación de los poderes Legislativo y Ejecutivo en cuanto a la iniciativa, propuesta y aprobación de las normativas en el ámbito de la 5ta Legislatura (2007-2010). Se trata de un estudio de naturaleza exploratoria- descriptiva que fue realizado a partir de un análisis documental. De las 2.515 propuestas legislativas que fueron presentadas en la Cámara Legislativa en la 5ta legislatura, 180 trataban temas de salud. Predominaron los proyectos de ley ordinarios, tanto de iniciativas generales como de salud. En cuanto al contenido de las normas, se observó una predominancia de propuesta tratando instituir políticas para control o para la atención de algunas enfermedades específicas $(38,4 \%)$. También hubo una predominancia de políticas sectoriales $(23,4 \%)$. Predominaron las normas de iniciativa del poder legislativo. Se concluye que los temas de salud tuvieron una frecuencia baja en la agenda del Poder Legislativo Distrital en la 5ta Legislatura y al analizarlas, se percibe que los principios y mandatos del SUS serian insuficientes para la prestación de la atención integral y resultaría necesario obligar, por medio de leyes específicas, a los gestores del SUS a que ofrezcan los servicios de salud que la población necesita.

Palabras-Ilave: Derecho a la Salud, Producción Legislativa, Sistema Único de Salud.

\section{Introdução}

A Constituição Federal de 1988 (CF/88) inaugurou um novo momento políticoinstitucional no Brasil, ao reafirmar o Estado democrático e definir uma política de proteção social abrangente. Reconheceu a saúde como direito social de cidadania e, com isso, a inscreveu no rol de um conjunto integrado de ações de iniciativa dos Poderes Públicos e da sociedade, voltados para assegurar nova ordem social, cujos objetivos precípuos são o bem-estar e a justiça sociais (1).

Para concretizar esse direito, a CF/88 criou o Sistema Único de Saúde (SUS), a partir de um modelo hierarquizado e regionalizado de ações e serviços públicos de saúde, organizados sob as diretrizes da descentralização, do atendimento integral e da participação social, conforme disposto em seu art. 198 (2).

A política de saúde do Distrito Federal se insere nesse contexto do SUS, que apresenta a descentralização como uma de suas diretrizes e que transfere, em parte, ao poder local, a responsabilidade das ações e serviços (3).

Para Dallari (4), o sistema de separação dos poderes, consagrado nas Constituições de quase todo o mundo, foi associado à ideia de Estado Democrático e deu origem a uma engenhosa construção doutrinária, conhecida como sistema de freios e contrapesos. Segundo essa teoria, os atos que o Estado pratica podem ser de duas espécies: ou são atos gerais ou são especiais. Os atos gerais, que só podem ser 
Cad. Ibero-Amer. Dir. Sanit., Brasília, v.4, n.3, jul./set. 2015 ISSN 2358-1824

praticados pelo Poder Legislativo, constituem a emissão de regras gerais e abstratas, não se sabendo, no momento de serem emitidas, a quem elas irão atingir (4).

Dessa forma, o Poder Legislativo, que só pratica atos gerais, não atua concretamente na vida social, não tendo meios para cometer abusos de poder nem para beneficiar ou prejudicar a uma pessoa ou a um grupo em particular. Só depois de emitida a norma geral é que se abre a possibilidade de atuação do Poder Executivo, por meio de atos especiais. O Executivo dispõe de meios concretos para agir, mas está igualmente impossibilitado de atuar discricionariamente, porque todos os seus atos estão limitados pelos atos gerais praticados pelo Legislativo. E, caso houver exorbitância de qualquer dos poderes, surge a ação fiscalizadora do Poder Judiciário, obrigando cada um a permanecer nos limites de sua respectiva esfera de competências (4).

Reconhecendo o Poder Legislativo como um importante ator social, este trabalho tem como objetivo analisar a contribuição da Câmara Legislativa Distrital para a política de saúde do Distrito Federal, caracterizando sua produção legislativa em matéria de saúde e a atuação dos poderes Legislativo e Executivo quanto à iniciativa, proposição, apreciação e aprovação daquelas matérias, no âmbito da 5ª legislatura (2007-2010).

\section{Metodologia}

Estudo de natureza exploratória e descritivo, a partir de análise documental, tendo como fonte de pesquisa as proposições legislativas apresentadas à Câmara Legislativa Distrital na 5a Legislatura, disponíveis no banco de dados da Câmara Legislativa Distrital - CLDF, acessáveis na internet pelo sítio eletrônico (sistema LEGIS) http://www.cl.df.gov.br/web/guest/proposicoes.

Segundo Gil (5), as pesquisas exploratórias têm como principal finalidade desenvolver, esclarecer e modificar conceitos e ideias, tendo em vista a formulação de problemas mais preciosos ou hipóteses pesquisáveis para estudos posteriores. São desenvolvidas com objetivo de proporcionar visão geral, de tipo aproximativo, acerca de determinado fato. Muitas vezes as pesquisas exploratórias constituem a primeira etapa de uma investigação mais ampla (5). Sobre os estudos descritivos, o autor destaca que essas pesquisas visam descobrir associações entre variáveis, para elucidar determinados resultados, por meio de técnicas padronizadas de coletas de dados. 
A análise da produção legislativa em saúde e da atuação da Câmara Distrital foi feita a partir da identificação da produção legislativa em saúde, quanto ao mérito e a espécie normativa - Projetos de Emenda à Lei Orgânica do Distrito Federal (PELO), Projetos de Lei Complementar (PLC), Projetos de Leis Ordinárias (PL) e Projetos de Decretos Legislativos (PDL), apresentados à Câmara Distrital na 5ª legislatura (2007 $-2010)$.

Quanto ao mérito, as proposições foram classificadas em cinco categorias básicas: políticas voltadas para o controle e/ou a assistência de agravos específicos; políticas Setoriais; gestão em saúde; simbólicas, honoríficas e outros.

Foram identificadas, no sítio eletrônico (sistema LEGIS) da Câmara Distrital, 2.515 proposições apresentadas na $5^{\underline{a}}$ legislatura, das quais 180 tratavam de matérias de saúde.

Para análise descritiva, foram levantadas as seguintes categorias: epígrafe; data de apresentação; resultado (aprovada, rejeitada, arquivada, vetada, apensada, tramitando); tempo de tramitação, ano e autoria.

Os achados foram tabulados em planilha eletrônica no formato Microsoft Excel, para análise e resultados.

\section{Resultados}

Foram apresentadas 2.515 proposições legislativas à CLDF na 5⿳亠丷厂 Legislatura, das quais 180 tratavam de matéria de saúde. A proporção de 7,1\%, evidencia que matérias de saúde ocuparam a agenda do Poder Legislativo Distrital com frequência, na legislatura estudada.

Quanto à espécie normativa, predominaram os Projetos de Lei Ordinária (172), tanto em termos gerais quanto em matéria de saúde. A baixa proporção de Projetos de Lei Complementar (3) e de Projetos de Emenda à Lei Orgânica (4), cuidando de matérias de saúde, é significativa de que elementos estruturais do sistema e da política já estavam estabelecidos; de um total de 575 Projetos de Decretos Legislativos, apenas 1 tratava de matéria de saúde, representando o menor percentual.

Quanto ao mérito, observou-se predomínio de proposições tratando de instituir políticas voltadas para o controle ou a atenção a agravos específicos $(38,4 \%)$ e políticas setoriais $(23,4 \%)$. Outros $18,4 \%$ estavam relacionados à gestão em saúde; e Projetos de Leis Simbólicas e Honoríficas tiveram um número pequeno (Tabela 1). 
Tabela 1 - Proposições legislativas sobre matérias de saúde apresentadas à Câmara Legislativa Distrital na $5^{\underline{a}}$ Legislatura, segundo a matéria e a espécie normativa. Brasília, 2007-2010.

\begin{tabular}{|c|c|c|c|c|c|c|c|c|c|c|}
\hline \multirow{2}{*}{ Categoria \espécie normativa } & \multicolumn{2}{|c|}{ PELO } & \multicolumn{2}{|c|}{ PLC } & \multicolumn{2}{|c|}{ PL } & \multicolumn{2}{|c|}{ PDL } & \multicolumn{2}{|c|}{ Total } \\
\hline & № & $\%$ & № & $\%$ & № & $\%$ & № & $\%$ & № & $\%$ \\
\hline \multirow{2}{*}{$\begin{array}{l}\text { Políticas } \mathrm{p} / \text { agravos específicos } \\
\text { Políticas setoriais }\end{array}$} & 1 & 0,6 & - & - & 68 & 37,7 & - & - & 69 & 38,4 \\
\hline & - & - & - & - & 42 & 23,3 & - & - & 42 & 23,4 \\
\hline \multirow{4}{*}{$\begin{array}{l}\text { Gestão em saúde } \\
\text { Leis simbólicas } \\
\text { Leis honoríficas } \\
\text { Outras }\end{array}$} & 2 & 1,1 & 4 & 2,2 & 27 & 15,0 & - & - & 33 & 18,4 \\
\hline & - & - & - & - & 5 & 2,8 & - & - & 5 & 2,8 \\
\hline & - & - & - & - & 1 & 0,6 & - & - & 1 & 0,6 \\
\hline & - & - & - & - & 29 & 16,1 & 1 & 0,6 & 30 & 16,7 \\
\hline Total & 3 & 1,7 & 4 & 2,2 & 172 & 95,5 & 1 & 0,6 & 180 & 100,0 \\
\hline
\end{tabular}

Fonte: Sistema LEGIS da Câmara Legislativa do Distrito Federal. Elaborada pela autora.

As proposições que trataram de matérias de saúde foram predominantemente apresentadas nos anos iniciais da Legislatura, em especial no ano de 2007, fato observado em relação a todas as categorias de mérito (Tabela 2).

Tabela 2 - Proposições legislativas sobre matérias de saúde apresentadas à Câmara Legislativa Distrital na 5ª Legislatura, segundo a matéria e o ano. Brasília, 2007-2010.

\begin{tabular}{|c|c|c|c|c|c|c|c|c|c|c|}
\hline \multirow{2}{*}{ Categoria \ano } & \multicolumn{2}{|c|}{2007} & \multicolumn{2}{|c|}{2008} & \multicolumn{2}{|c|}{2009} & \multicolumn{2}{|c|}{2010} & \multicolumn{2}{|c|}{ Total } \\
\hline & № & $\%$ & & $\%$ & & $\%$ & № & $\%$ & № & $\%$ \\
\hline Políticas p/ agravos específicos & 42 & 42,0 & 14 & 35,9 & 9 & 34,7 & 4 & 25,0 & 69 & 38,0 \\
\hline Políticas setoriais & 22 & 22,0 & 14 & 35,9 & 3 & 11,6 & 3 & 18,8 & 42 & 23,0 \\
\hline Gestão em saúde & 14 & 14,0 & 3 & 7,7 & 9 & 34,7 & 7 & 43,8 & 33 & 18,0 \\
\hline Leis simbólicas & 3 & 3,0 & 1 & 2,6 & - & - & 1 & 6,0 & 5 & 2,8 \\
\hline Leis honoríficas & & & 1 & 2,6 & - & - & - & - & 1 & 0,6 \\
\hline Outros & 18 & 18,0 & 6 & 15,0 & 5 & 19,0 & 1 & 6,0 & 30 & 16,7 \\
\hline Total & 99 & 55,0 & 39 & 21,7 & 26 & 14,4 & 16 & 8,9 & 180 & 100,0 \\
\hline
\end{tabular}

Fonte: Sistema LEGIS da Câmara Legislativa do Distrito Federal. Elaborada pela autora.

Das 180 matérias de saúde apresentadas à CLDF na legislatura estudada, predominaram as de iniciativa do Legislativo, com exceção daquelas voltadas para gestão, em razão da reserva constitucional de iniciativa do Executivo. Ocorre que as proposições de políticas, tanto as voltadas para agravos específicos quanto de políticas setoriais são quase que, exclusivamente, de iniciativa do Legislativo (68 das 69 proposições de políticas específicas e 41 das 42 políticas setoriais). A proposição de Leis Simbólicas e Honoríficas foram todas de iniciativa do Poder Legislativo (Tabela 3). 
Tabela 3 - Proposições legislativas sobre matérias de saúde apresentadas à Câmara Legislativa Distrital na $5^{\text {a }}$ Legislatura, segundo a categoria de matéria e a iniciativa. Brasília, 2007-2010.

\begin{tabular}{|c|c|c|c|c|}
\hline \multirow{2}{*}{ Iniciativa/Categoria } & Legislativo & Executivo & \multicolumn{2}{|c|}{ Total } \\
\hline & № $\quad \%$ & № $\%$ & № & $\%$ \\
\hline Políticas voltadas $\mathrm{p} /$ agravos específicos & $68 \quad 37,8$ & 10,6 & 69 & 34,4 \\
\hline Políticas setoriais & 4122,8 & 13,0 & 42 & 23,3 \\
\hline Gestão em saúde & $6 \quad 3,3$ & 2715,0 & 33 & 18,3 \\
\hline Simbólicas & 2,8 & $-\quad-$ & 5 & 2,8 \\
\hline Honorífica & 0,6 & - & 1 & 0,6 \\
\hline Outras & 16,1 & 10,6 & 30 & 16,7 \\
\hline Total & $150 \quad 83,3$ & 3016,7 & 180 & 100,0 \\
\hline
\end{tabular}

Fonte: Sistema LEGIS da Câmara Legislativa do Distrito Federal. Elaborada pela autora

Das matérias de saúde, quanto à iniciativa, predominaram as oriundas do Poder Legislativo. Quanto ao resultado, as matérias foram arquivadas ou estavam tramitando. Quanto ao resultado das matérias de saúde de iniciativa do Poder Executivo, os projetos foram sancionados (Tabela 4).

Tabela 4 - Proposições legislativas sobre matérias de saúde apresentadas à Câmara Legislativa Distrital na $5^{\underline{a}}$ Legislatura, segundo a iniciativa e o resultado. Brasília, 20072010.

\begin{tabular}{|c|c|c|c|c|c|c|}
\hline \multirow[t]{2}{*}{ Iniciativa/Resultados } & \multicolumn{2}{|c|}{ Legislativo } & \multicolumn{2}{|c|}{ Executivo } & \multicolumn{2}{|c|}{ Total } \\
\hline & $\mathrm{No}$ & $\%$ & & $\%$ & & $\%$ \\
\hline Retirado & 7 & 4,7 & 6 & 20,0 & 13 & 7,2 \\
\hline Apensado & 2 & 1,3 & 1 & 3,3 & 3 & 1,7 \\
\hline Arquivado & 37 & 24,7 & 4 & 13,3 & 41 & 22,8 \\
\hline Prejudicado & 7 & 4,7 & - & - & 7 & 3,9 \\
\hline Aprovado & 4 & 2,7 & . & - & 4 & 2,2 \\
\hline Promulgado & 5 & 3,3 & 2 & 6,7 & 7 & 3,9 \\
\hline Sancionado & 26 & 17,3 & 17 & 56,7 & 43 & 23,9 \\
\hline Vetado & 5 & 3,3 & - & - & 5 & 2,8 \\
\hline Tramitando & 57 & 38,0 & - & - & 57 & 31,7 \\
\hline Total & 150 & 100,00 & 30 & 100,0 & 180 & 100,0 \\
\hline
\end{tabular}

Fonte: Sistema LEGIS da Câmara Legislativa do Distrito Federal. Elaborada pela autora. 
Das matérias de saúde, quanto à frequência de matérias apresentadas à CLDF na legislatura estudada, 12 tratavam do tema drogas; seguido dos temas educação e saúde e câncer (Tabela 5).

Tabela 5 - Proposições legislativas sobre matérias de saúde apresentadas à Câmara Legislativa Distrital na 5aㅡ Legislatura, segundo a matéria. Brasília, 2007-2010.

\begin{tabular}{l|cc}
\hline Frequência/matérias & № & $\%$ \\
\hline Drogas & 12 & 6,7 \\
Educação e saúde & 10 & 5,6 \\
Câncer (controle) & 8 & 4,0 \\
Vencimento de carreira & 7 & 3,9 \\
Saúde do trabalhador & 6 & 3,0 \\
Gratificação salarial & 5 & 2,8 \\
Reabilitação & 4 & 2,0 \\
Medicamentos & 4 & 2,0 \\
Saúde da mulher & 4 & 2,0 \\
Visão & 3 & 1,7 \\
Saúde da criança & 3 & 1,7 \\
Recursos humanos & 2 & 1,0 \\
Carreira assistencial & 2 & 1,0 \\
Criação de cargos & 2 & 1,0 \\
Outros & 108 & 60,0 \\
\hline Total & 180 & 100,0 \\
\hline
\end{tabular}

Fonte: Sistema LEGIS da Câmara Legislativa do Distrito Federal. Elaborada pela autora.

\section{Discussão}

Nas últimas décadas, a sociedade brasileira vem passando por notável transformação, o que confere heterogeneidade estrutural à sociedade, refletindo nas estruturas social, política e econômica do país (6).

As proposições legislativas apresentadas à CLDF na legislatura estudada, quanto às matérias de saúde, foram propostas na sua quase totalidade na forma de Lei Ordinária, isto é, as chamadas leis comuns que são elaboradas pelo Congresso Nacional (na esfera federal), ou pela Assembleia Legislativa (na esfera estadual), ou pela Câmara dos Vereadores (na esfera municipal).

O Poder Legislativo destaca-se como principal propositor de matérias que tratam de políticas voltadas para o controle e assistência de agravos específicos (37, 8\%) e de políticas setoriais $(22,8 \%)$. Os temas que apareceram com maior frequência 
com matérias de proposições foram os relativos às políticas voltadas para o combate às drogas; educação e saúde; e controle de cânceres (colo do útero, mama e bucal).

Observa-se que as proposições legislativas da Câmara Distrital em matéria de saúde, na legislatura estudada, têm favorecido grupos específicos e determinadas patologias, ou seja, os projetos propõem algo que está previsto na Lei no8. 080, de 1990, que estabelece a integralidade da assistência como um dos princípios do Sistema Único de Saúde, um conjunto articulado e contínuo de ações e serviços preventivos e curativos, individuais e coletivos, exigidos para cada caso em todos os níveis de atenção.

A integralidade refere-se ao acesso de todo e qualquer cidadão brasileiro ao Sistema Único de Saúde, desde a prevenção, promoção, reabilitação e aos serviços de alta complexidade, quando houver necessidade de assistência.

O interessante é que essas leis trazem o que a Lei Orgânica da Saúde determina de forma geral e abstrata. Será que, para concretizar o direito à saúde, frente a uma patologia específica, é necessário explicitar a patologia? Nesse mesmo pensamento, Lucchese questiona se 'há necessidade de termos uma lei para cada tipo de patologia para que o SUS a venha atender?' (2).

Essas leis são frutos de iniciativas de parlamentares que, na maioria das vezes, não tem relação com as necessidades da população, nem obedecem aos critérios epidemiológicos, que são instrumentos que devem guiar a alocação de recursos, sempre escassos, para a saúde da população. Os critérios são unicamente políticos se é que se pode chamar de critérios - de interesse de um grupo social ou parlamentar (2).

Outra questão é como essas demandas estão chegando aos parlamentares e de que forma esses grupos com interesses focalizados conseguem que suas demandas cheguem ao conhecimento dos parlamentares (2).

As instâncias de gestão do SUS e os profissionais de saúde não precisam de leis que especifiquem o que se deve fazer nos procedimentos de média e alta complexidade, visto que é de entendimento de todos, pois está previsto na Lei Orgânica da Saúde (2).

O princípio do acesso universal é a expressão de que todos têm o mesmo direito de obter as ações e os serviços dos quais necessitam, independente da complexidade, custo e natureza dos serviços envolvidos. Com a universalidade, as 
Cad. Ibero-Amer. Dir. Sanit., Brasília, v.4, n.3, jul./set. 2015 ISSN 2358-1824

condições socioeconômicas da população e a inserção no mercado de trabalho não devem implicar acesso diferenciado a determinados tipos de serviços: as despesas com os riscos de adoecimento e o financiamento passam a ser repartidos de forma solidária, entre grupos de diferentes classes de renda, sendo de responsabilidade de toda a sociedade (7).

Ainda segundo Noronha (7), o princípio da integralidade é entendido, nos termos da lei, como um conjunto articulado e contínuo de ações e serviços preventivos e curativos, individuais e coletivos, exigindo para cada caso todos os níveis de complexidade do sistema. E para firmar esse princípio, o art. 196 da CF/88 é bem claro, quando afirma que é dever do estado a prestação de assistência à saúde, garantindo o acesso universal e igualitário do cidadão aos serviços e ações para sua promoção, proteção e recuperação. O direito à saúde, como está assegurado na Carta Magna, não deve sofrer embaraços impostos por autoridades administrativas, no sentido de reduzi-lo ou de dificultar o acesso a ele (2).

É certo que o conceito de integralidade precisa de uma definição que lhe agregue racionalidade no seu uso no âmbito do direito à saúde. Não deve significar qualquer coisa para qualquer pessoa. Isso seria a negação da natureza científica e racional da organização dos serviços de saúde, em qualquer de suas formas e contextos. A integralidade precisa ser regulada segundo cânones políticos e administrativos e consensos científicos (2).

O que se verifica é que mesmo sendo um direito garantido pela Constituição e pela Lei Orgânica da Saúde, parece que o SUS não tem dado conta de resolver problemas que a população vem sofrendo, seja na prestação de serviços ou na garantia de direitos pelo Estado, sendo necessária aprovação de leis que obrigue o SUS a fornecer medicamentos e criação de programas voltados para determinadas patologias (2).

Godoi (8) afirma que essas leis que definem políticas voltadas para agravos específico, produzidas por parte do Legislativo, devem ser uma tentativa de corrigir falhas e deficiências de cobertura do sistema público de saúde, respondendo a demandas de grupos específicos de usuários do SUS. Com a redemocratização, os grupos de interesse passam a ter um espaço privilegiado de atuação dentro do parlamento, entre os quais figuram os portadores de patologias e usuários do SUS. Analisar a relação dos grupos de interesse com os parlamentares, a que grupos estão vinculados ou representam, é uma abordagem importante no sentido de entender a 
Cad. Ibero-Amer. Dir. Sanit., Brasília, v.4, n.3, jul./set. 2015 ISSN 2358-1824

preferência dos parlamentares por esse tipo de proposição.

Os direitos sociais precisam de regulamentos claros, que permitam aos cidadãos ter consciência deles e da forma como os mesmos serão providos pelo Estado. No entanto, aprovar uma lei específica para cada grupo de interesses, não seria condição suficiente para sua efetivação (2).

A inclinação do Legislativo em favor de demandas de segmentos populacionais, definidos por atributos específicos, ao lado do debate e elaboração de leis de interesse geral admite diferentes interpretações. A criação de dias dedicados a portadores de patologias, como são os casos das leis simbólicas, tem sido encarada ora como um sintoma da hesitação sobre efetividade da universalização pretendida pelo SUS, ora como expressão da capacidade de absorver e até antecipar a diversificação das necessidades e interesses da sociedade brasileira (9).

Ainda segundo Bahia (9) há uma inclinação do Poder Legislativo em favorecer demandas de segmentos populacionais específicos, relacionados aos problemas de cobertura, enquanto o Executivo está mais voltado a encaminhar projetos de caráter geral e estruturante do sistema de saúde.

Percebe-se que atuação do Poder Executivo foi expressiva nas proposições referentes à categoria gestão do Sistema Único de Saúde (Tabela 3). Isso porque a função típica do Poder Executivo é exercer a administração pública do Estado.

O Executivo se sobressai no processo legislativo porque tem poder de agenda, e esta agenda é processada e votada por um Poder Legislativo, organizado de forma altamente centralizada em torno de regras que distribuem direitos parlamentares, de acordo com princípios partidários. Pois, no interior deste quadro institucional, o presidente conta com os meios para induzir os parlamentares à cooperação (11).

É preciso compreender melhor a dinâmica do presidencialismo de coalizão no Brasil. A Nova República repete a de 1946 que, por sua vez, provavelmente manteve resquícios da República Velha, sobretudo no que diz respeito à influência dos estados no governo federal, pela via da 'política de governadores'. A lógica de formação das coalizões tem, nitidamente, dois eixos: o partidário e o regional (estadual), hoje como ontem. É isto que explica a recorrência de grandes coalizões, pois o cálculo relativo à base de sustentação política do governo não é apenas partidário parlamentar, mas também regional (6).

É um sistema caracterizado pela instabilidade de alto risco e cuja sustentação baseia-se, quase que exclusivamente, no desempenho corrente do governo e na sua 
Cad. Ibero-Amer. Dir. Sanit., Brasília, v.4, n.3, jul./set. 2015 ISSN 2358-1824

disposição de respeitar estritamente os pontos ideológicos ou programáticos considerados inegociáveis, os quais nem sempre são explícita e coerentemente fixados na fase de formação da coalizão (6).

A força do Executivo é identificada tanto na ação legislativa típica quanto na ação da burocracia estatal, mediante a edição de normas infralegais que, muitas vezes, promovem verdadeiras modificações nas políticas aprovadas pelo Congresso. É amplamente aceito que o presidencialismo brasileiro está pautado fortemente na figura do presidente, que detém amplo poder legislativo concedido pela Constituição Federal. De acordo com Figueiredo (10), 86\% das leis produzidas em 1989 foram originárias do Poder Executivo (8).

No plano macropolítico, verifica-se a permanência das formas mais atrasadas de clientelismo ao lado de padrões de comportamento ideologicamente estruturados. Há um claro 'pluralismo de valores', com os quais diferentes grupos associam expectativas e valorações diversas às instituições, produzindo avaliações acentuadamente distintas acerca da eficácia e da legitimidade dos instrumentos de representação e participação típicos das democracias liberais. Não se obtém, portanto, a adesão generalizada a um determinado perfil institucional, a um modo de organização, funcionamento e legitimação da ordem política (6).

A teoria empírica das coalizões de Abranches (6), embora excessivamente descritiva e assentada na lógica das preferências individuais, permite identificar algumas questões que ajudam a compreensão da intrincada dinâmica política e institucional associada aos governos de aliança. Em geral, a análise de estruturas políticas e sociais mais homogêneas e estáveis induz a uma ênfase maior em coalizões que minimizem o número de parceiros e maximizem as proximidades ideológicas entre eles (6).

Os dados revelam que uma das principais diferenças entre as proposições de autoria do Executivo e do Legislativo está no fato de o Executivo ter praticamente exclusividade na formulação de proposições voltadas para organização e gestão do SUS (2).

Outra diferença importante entre os dois Poderes foi em relação às leis simbólicas e honoríficas. A totalidade desse tipo de lei originou do Poder Legislativo. Não havendo leis dessa natureza no Poder Executivo (2).

No que se refere a esse estudo, as proposições classificadas como categorias de gestão de saúde ficaram restritas a gratificações, criação de cargos e vencimento de 
Cad. Ibero-Amer. Dir. Sanit., Brasília, v.4, n.3, jul./set. 2015 ISSN 2358-1824

carreira. Ou seja, proposições com maior foco nos recursos humanos do Sistema Único de Saúde.

Outro dado interessante é que todos os projetos de iniciativa do Executivo foram apresentados em caráter de urgência. O que, segundo Figueiredo e Limongi (10), além de alterar o ritmo da tramitação, retirando da comissão e forçando a pronta manifestação do plenário, a aprovação de requerimento de urgência limita a capacidade dos próprios parlamentares de apresentarem emendas ao projeto.

Matérias com regime de urgência tramitam rapidamente por ambas as casas, o que implica pequena participação dos parlamentares na elaboração das leis aprovadas (10).

A Constituição de 1988, no que diz respeito ao Poder Legislativo, aprovou dois conjuntos distintos e, podem-se definir contraditórios de medidas. De um lado, os constituintes aprovaram uma série de medidas tendentes a fortalecer o Congresso, recuperando assim os poderes subtraídos do Legislativo ao longo do período militar; de outro lado, a Constituição de 1988 manteve muitos dos poderes legislativos com os quais o Poder Executivo foi dotado ao longo do período autoritário. Dessa forma, não foram revogadas muitas das prerrogativas que permitiram ao Executivo dirigir o processo legislativo durante o regime militar (10).

De acordo com Baptista (12) ainda há um longo caminho a ser trilhado no processo político-institucional, de modo a garantir a independência e harmonia entre os poderes. Sendo uma questão fundamental em relação a esse caminho a busca de um maior balanceamento de poder dentro do próprio legislativo, que mantém um padrão altamente centralizado de organização, favorecendo o apoio legislativo à agenda Executiva em bases partidárias. 


\section{Conclusões}

Observou-se que matérias de saúde ocuparam com baixa frequência a agenda do Poder Legislativo Distrital na 5 ${ }^{\underline{a}}$ Legislatura, no entanto, ao analisá-las, percebe-se que os princípios e mandamentos do SUS talvez não tenham alcançado seus objetivos, sendo necessário obrigar, por meio de leis específicas, os gestores do SUS a oferecerem os serviços de saúde de que a população necessita.

As proposições estudadas refletem um estado de ânimo da sociedade quanto ao Sistema Único de Saúde. Parece-nos que o objetivo dos proponentes dessas matérias de saúde é fazer com que o SUS cumpra o que propõe: a atenção integral à saúde de cada cidadão e da população em geral, no conjunto de suas necessidades.

Talvez essas leis voltadas para problemas específicos, possam, no longo prazo, se refletir em conquista da sociedade. Pois o SUS, sendo pressionado, talvez ofereça melhores serviços à população. Corre, no entanto, o risco de se tornar um sistema fragmentado e gerar desigualdades sociais.

\section{Referências Bibliográficas}

1 Baptista TWF, Machado CV, Lima LD. Responsabilidade do Estado e direito à saúde no Brasil: um balanço da atuação dos Poderes. Ciências \& Saúde Coletiva [Internet]. 2009 [Acesso em: 10 jun. 2014] 14(3): 829-839. Disponível em http://www.scielo.br/pdf/csc/v14n3/18.pdf.

2 Lucchese G. Proliferação Legislativa no setor saúde: Conquista ou impasse? Cadernos Ibero-Americanos de Direito Sanitário [Internet]. 2013 [Acesso em 10 jun 2014] 2(1): 1-21. Disponível em http://www.cadernos.prodisa.fiocruz.br/index.php/cadernos/article/view/27/75.

3 Betini G. A produção legislativa em saúde da Câmara Distrital no ano de 2008. In: Romero L.C; Delduque MC, organizadores. Estudos de Direito Sanitário: a produção normativa em saúde. Brasília: Senado Federal: Subsecretaria de Edições Técnicas, 2011. $214 \mathrm{p}$.

4 Dallari DA. Elementos da teoria geral do Estado [Internet]. São Paulo: Saraiva; 1997. [Acesso em 1o out 2014]. Disponível em:

http://pt.slideshare.net/pholwe/elementosdeteoriageraldoestadodalmodeabreudallarip ootzorg.

5 GIL AC. Métodos e técnicas de pesquisa social. São Paulo :Atlas; 1999. 
6 Abranches SHH. Presidencialismo de coalizão: o dilema institucional brasileiro. Revista de Ciências Sociais [Internet]. 1988 [Acesso em 05 set 2014] 31: 5-34. Disponível em http://politica3unifesp.files.wordpress.com/2013/01/74783229presidencialismo-de-coalizao-sergio-abranches.pdf.

7 Noronha C J et al. O Sistema Único de Saúde. In: Giovanella L, organizadora. Políticas e sistemas de saúde no Brasil. Rio de Janeiro: Fiocruz; 2012. p. 365-393.

8 Godoi AMM. Executivo e Legislativo na Produção Legal em Saúde, de 1988 a 2008. In: Romero LC; Delduque MC, organizadores. Estudos de Direito Sanitário: a produção normativa em saúde. Brasília: Senado Federal: Subsecretaria de Edições Técnicas; 2011. $214 \mathrm{p}$.

9 Bahia L, Costa NR, Stralen C. A saúde na agenda pública: convergências e lacunas nas pautas de debate e programas de trabalho das instituições governamentais e movimentos sociais. Ciência \& Saúde Coletiva [Internet]. 2007 [Acesso em 10 jul 2014] 12: 1791-1818. Disponível em http://www.scielosp.org/pdf/csc/v12s0/04.pdf.

10 Figueiredo A C, Limongi E. Mudança constitucional, desempenho do legislativo e consolidação institucional. Revista Brasileira de Ciências Sociais [Internet]. 1995 [Acesso em 12 jun 2014] 29: 175-200. Disponível em http://pmcspraca.files.wordpress.com/2013/01/figueiredo-e-limongi-1999.pdf.

11 . Executivo e legislativo na nova ordem constitucional [Internet]. Rio de Janeiro: Editora FGV, 2001. [Acesso em 12 jun 2014]. Disponível em: http://pmcspraca.files.wordpress.com/2013/01/figueiredo-e-limongi-1999.pdf.

12 Baptista TWF. Análise da produção legislativa em saúde no Congresso Nacional brasileiro (1990-2006). Cadernos de Saúde Pública [Internet]. 2010 [Acesso em 03 jun 2014] 26(1): 97-109. Disponível em http://www.scielo.br/pdf/csp/v26n1/11.pdf. 